\title{
ON A CLASS OF HOLOMORPHIC FUNCTIONS DEFINED BY THE RUSCHEWEYH DERIVATIVE
}

\section{GEORGIA IRINA OROS}

Received 23 September 2002

By using the Ruscheweyh operator $D^{m} f(z), z \in U$, we will introduce a class of holomorphic functions, denoted by $M_{n}^{m}(\alpha)$, and obtain some inclusion relations.

2000 Mathematics Subject Classification: 30C45.

1. Introduction and preliminaries. Denote by $U$ the unit disc of the complex plane

$$
U=\{z \in \mathbb{C} ;|z|<1\} .
$$

Let $\mathscr{H}(U)$ be the space of holomorphic functions in $U$.

We let

$$
A_{n}=\left\{f \in \mathscr{H}(U), f(z)=z+a_{n+1} z^{n+1}+\cdots, z_{1} \in U\right\}
$$

with $A_{1}=A$.

We let $\mathscr{H}[a, n]$ denote the class of analytic functions in $U$ of the form

$$
f(z)=a+a_{n} z^{n}+a_{n+1} z^{n+1}+\cdots, \quad z \in U .
$$

If $f$ and $g$ are analytic in $U$, we say that $f$ is subordinate to $g$, written $f \prec g$ or $f(z) \prec g(z)$, if there is a function $w$ analytic in $U$, with $w(0)=0,|w(z)|<1$, for any $z \in U$, such that $f(z)=g(w(z))$, for $z \in U$.

If $g$ is univalent, then $f \prec g$ if and only if $f(0)=g(0)$ and $f(U) \subset g(U)$.

Let $K=\left\{f \in A: \operatorname{Re}\left(z f^{\prime \prime}(z) / f^{\prime}(z)\right)+1>0, z \in U\right\}$ denote the class of normalized convex functions in $U$. We use the following subordination results.

LEMMA 1.1 (Miller and Mocanu [2, page 71]). Let $h$ be a convex function with $h(0)=a$ and let $\gamma \in \mathbb{C}^{*}$ be a complex with $\operatorname{Re} \gamma \geq 0$. If $p \in \mathscr{H}[a, n]$ and

$$
p(z)+\frac{1}{\gamma} z p^{\prime}(z) \prec h(z)
$$


then $p(z) \prec g(z) \prec h(z)$, where

$$
g(z)=\frac{\gamma}{n z^{\gamma / n}} \int_{0}^{z} h(t) \cdot t^{(\gamma / n)-1} d t
$$

The function $g$ is convex and is the best $(a, n)$ dominant.

LEMMA 1.2 (Miller and Mocanu [1]). Let $g$ be a convex function in $U$ and let

$$
h(z)=g(z)+n \alpha z g^{\prime}(z),
$$

where $\alpha>0$ and $n$ is a positive integer. If $p(z)=g(0)+p_{n} z^{n}+\cdots$ is holomorphic in $U$ and

$$
p(z)+\alpha z p^{\prime}(z) \prec h(z)
$$

then

$$
p(z) \prec g(z)
$$

and this result is sharp.

Definition 1.3 [4]. For $f \in A$ and $m \geq 0$, the operator $D^{m} f$ is defined by

$$
D^{m} f(z)=f(z) * \frac{z}{(1-z)^{m+1}}=\frac{z}{m !}\left[z^{m-1} f(z)\right]^{(m)}, \quad z \in U
$$

where $*$ stands for convolution.

REMARK 1.4. We have

$$
\begin{gathered}
D^{0} f(z)=f(z), \quad z \in U, \\
D^{1} f(z)=z f^{\prime}(z), \quad z \in U, \\
2 D^{2} f(z)=z \cdot\left[D^{1} f(z)\right]^{\prime}+D^{1} f(z), \\
(m+1) D^{m+1} f(z)=z\left[D^{m} f(z)\right]^{\prime}+m D^{m} f(z) .
\end{gathered}
$$

\section{Main results}

DEFINITION 2.1. If $\alpha<1$ and $m, n \in \mathbb{N}$, let $M_{n}^{m}(\alpha)$ denote the class of functions $f \in A_{n}$ which satisfy the inequality

$$
\operatorname{Re}\left(D^{m} f\right)^{\prime}(z)>\alpha
$$

THEOREM 2.2. If $\alpha<1$ and $m, n \in \mathbb{N}$, then

$$
M_{n}^{m+1}(\alpha) \subset M_{n}^{m}(\delta),
$$


where

$$
\begin{gathered}
\delta=\delta(\alpha, n, m)=2 \alpha-1+2 \cdot(1-\alpha) \cdot \frac{m+1}{n} \beta\left(\frac{m+1}{n}\right), \\
\beta(x)=\int_{0}^{1} \frac{t^{x-1}}{1+t} d t .
\end{gathered}
$$

Proof. Let $f \in M_{n}^{m+1}(\alpha)$. By using the properties of the operator $D^{m} f(z)$, we have

$$
(m+1) D^{m+1} f(z)=z \cdot\left(D^{m} f\right)^{\prime}(z)+m D^{m} f(z), \quad z \in U .
$$

Differentiating (2.4), we obtain

$$
\begin{aligned}
(m+1)\left[D^{m+1} f(z)\right]^{\prime} & =z \cdot\left(D^{m} f\right)^{\prime \prime}(z)+\left(D^{m} f\right)^{\prime}(z)+m\left(D^{m} f\right)^{\prime}(z) \\
& =z\left(D^{m} f\right)^{\prime \prime}(z)+(m+1)\left(D^{m} f\right)^{\prime}(z)
\end{aligned}
$$

If we let $p(z)=\left(D^{m} f\right)^{\prime}(z)$, then $p^{\prime}(z)=\left(D^{m} f\right)^{\prime \prime}(z)$ and (2.4) becomes

$$
\left[D^{m+1} f(z)\right]^{\prime}=p(z)+\frac{1}{m+1} z \cdot p^{\prime}(z) .
$$

Since $f \in M_{n}^{m+1}(\alpha)$, by using Definition 2.1, we have

$$
\operatorname{Re}\left[p(z)+\frac{1}{m+1} z p^{\prime}(z)\right]>\alpha
$$

which is equivalent to

$$
p(z)+\frac{1}{m+1} z p^{\prime}(z) \prec \frac{1+(2 \alpha-1) z}{1+z} \equiv h(z) .
$$

By using Lemma 1.1, we have

$$
p(z) \prec g(z) \prec h(z),
$$

where

$$
g(z)=\frac{m+1}{n z^{(m+1) / n}} \int_{0}^{z} \frac{1+(2 \alpha-1) t}{1+t} \cdot t^{(m+1) / n-1} d t .
$$

The function $g$ is convex and is the best dominant.

From $p(z) \prec g(z)$, it results that

$$
\operatorname{Re} p(z)>\delta=g(1)=\delta(\alpha, n, m),
$$


where

$$
\begin{aligned}
g(1) & =\frac{m+1}{n} \int_{0}^{1} t^{(m+1) / n-1} \cdot \frac{1+(2 \alpha-1) t}{1+t} d t \\
& =2 \alpha-1+2 \cdot \frac{m+1}{n} \cdot(1-\alpha) \beta\left(\frac{m+1}{n}\right),
\end{aligned}
$$

from which we deduce that $M_{n}^{m+1}(\alpha) \subset M_{n}^{m}(\delta)$.

For $n=1$, this result was obtained in [3].

THEOREM 2.3. Let $g$ be a convex function, $g(0)=1$, and let $h$ be a function such that

$$
h(z)=g(z)+\frac{1}{m+1} z g^{\prime}(z)
$$

If $f \in A_{n}$ and verifies the differential subordination

$$
\left(D^{m+1} f\right)^{\prime}(z) \prec h(z)
$$

then

$$
\left(D^{m} f\right)^{\prime}(z) \prec g(z)
$$

Proof. From

$$
(m+1) D^{m+1} f(z)=z \cdot\left(D^{m} f\right)^{\prime}(z)+m D^{m} f(z),
$$

we obtain

$$
\begin{aligned}
(m+1)\left[D^{m+1} f(z)\right]^{\prime} & =\left(D^{m} f\right)^{\prime}(z)+z\left(D^{m} f\right)^{\prime \prime}(z)+m\left(D^{m} f\right)^{\prime}(z) \\
& =z\left(D^{m} f\right)^{\prime \prime}(z)+(m+1)\left(D^{m} f\right)^{\prime}(z) .
\end{aligned}
$$

If we let $p(z)=\left(D^{m} f\right)^{\prime}(z)$, then we obtain

$$
\left[D^{m+1} f(z)\right]^{\prime}=p(z)+\frac{1}{m+1} z p^{\prime}(z)
$$

and (2.14) becomes

$$
p(z)+\frac{1}{m+1} z p^{\prime}(z) \prec g(z)+\frac{1}{m+1} z g^{\prime}(z) \equiv h(z) .
$$

By using Lemma 1.2, we have

$$
p(z) \prec g(z) \text {, i.e., }\left(D^{m} f\right)^{\prime}(z) \prec g(z) .
$$

For $n=1$, this result was obtained in [3]. 
THEOREM 2.4. Let $h \in \mathscr{H}[U]$, with $h(0)=1, h^{\prime}(0) \neq 0$, which verifies the inequality

$$
\operatorname{Re}\left[1+\frac{z h^{\prime \prime}(z)}{h^{\prime}(z)}\right]>-\frac{1}{2(m+1)}, \quad m \geq 0 .
$$

If $f \in A_{n}$ and verifies the differential subordination

$$
\left[D^{m+1} f(z)\right]^{\prime} \prec h(z), \quad z \in U,
$$

then

$$
\left[D^{m} f(z)\right]^{\prime} \prec g(z)
$$

where

$$
g(z)=\frac{m+1}{n z^{(m+1) / n}} \int_{0}^{z} h(t) t^{(m+1) / n-1} d t .
$$

The function $g$ is convex and is the best dominant.

Proof. A simple application of the differential subordination technique $[1,2]$ shows that the function $g$ is convex. From

$$
(m+1) D^{m+1} f(z)=z\left[D^{m} f(z)\right]^{\prime}+m D^{m} f(z),
$$

we obtain

$$
(m+1)\left[D^{m+1} f(z)\right]^{\prime}=z\left[D^{m} f(z)\right]^{\prime \prime}+(m+1)\left[D^{m} f(z)\right]^{\prime} .
$$

If we let $p(z)=\left[D^{m} f(z)\right]^{\prime}$, then we obtain

$$
\left[D^{m+1} f(z)\right]^{\prime}=p(z)+\frac{1}{m+1} z p^{\prime}(z)
$$

and (2.22) becomes

$$
p(z)+\frac{1}{m+1} z p^{\prime}(z) \prec h(z) .
$$

By using Lemma 1.1, we have

$$
p(z) \prec g(z)=\frac{m+1}{n z^{(m+1) / n}} \int_{0}^{z} h(t) t^{(m+1) / n-1} d t .
$$

THEOREM 2.5. Let $g$ be a convex function, $g(0)=1$, and

$$
h(z)=g(z)+n z g^{\prime}(z) .
$$

If $f \in A_{n}$ and verifies the differential subordination

$$
\left[D^{m} f(z)\right]^{\prime} \prec h(z), \quad z \in U
$$


then

$$
\frac{D^{m} f(z)}{z} \prec g(z)
$$

Proof. We let $p(z)=D^{m} f(z) / z, z \in U$, and we obtain

$$
D^{m} f(z)=z p(z)
$$

By differentiating, we obtain

$$
\left[D^{m} f(z)\right]^{\prime}=p(z)+z p^{\prime}(z), \quad z \in U .
$$

Then (2.31) becomes

$$
p(z)+z p^{\prime}(z) \prec h(z)=g(z)+z g^{\prime}(z)
$$

By using Lemma 1.2, we have (1.8).

\section{REFERENCES}

[1] S. S. Miller and P. T. Mocanu, On some classes of first-order differential subordinations, Michigan Math. J. 32 (1985), no. 2, 185-195.

[2] _ Differential Subordinations. Theory and Applications, Monographs and Textbooks in Pure and Applied Mathematics, vol. 225, Marcel Dekker, New York, 2000.

[3] Gh. Oros and G. I. Oros, A class of holomorphic functions, Automat. Comput. Appl. Math. 11 (2002), no. 2, 77-80.

[4] St. Ruscheweyh, New criteria for univalent functions, Proc. Amer. Math. Soc. 49 (1975), 109-115.

Georgia Irina Oros: Faculty of Mathematics and Computer Science, Babeş-Bolyai University, 400084 Cluj-Napoca, Romania

E-mail address: georgia_oros_ro@yahoo.com 


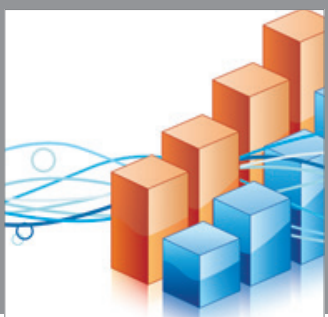

Advances in

Operations Research

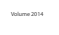

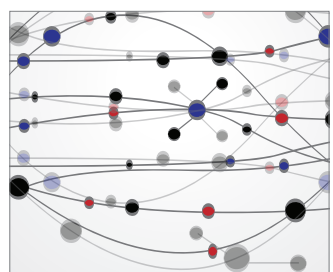

\section{The Scientific} World Journal
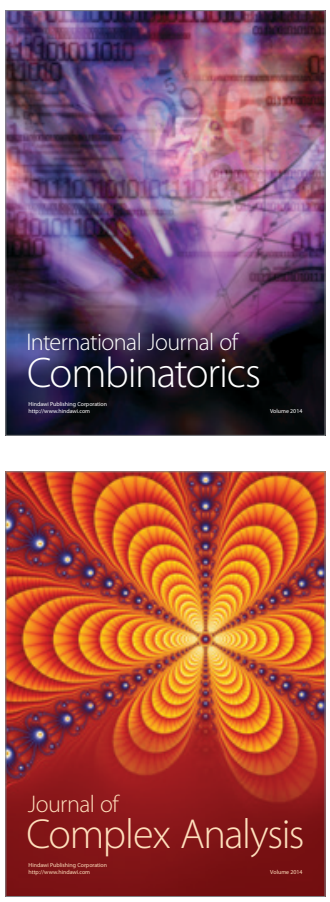

International Journal of

Mathematics and

Mathematical

Sciences
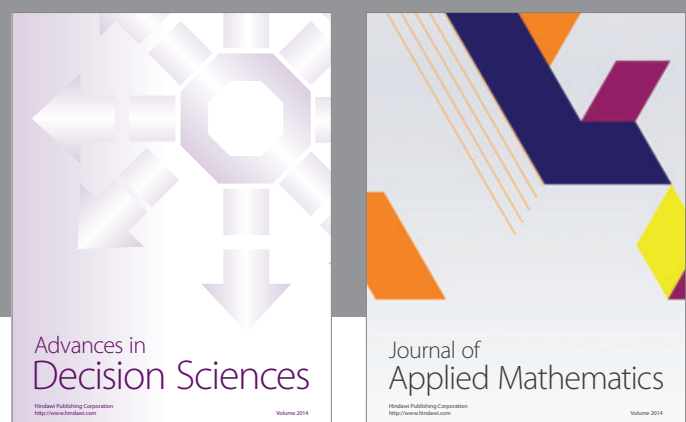

Journal of

Applied Mathematics
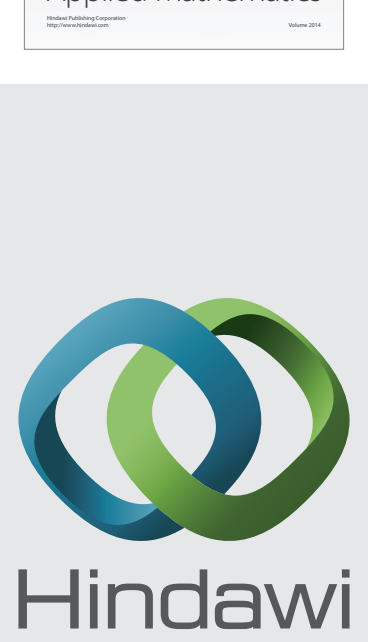

Submit your manuscripts at http://www.hindawi.com
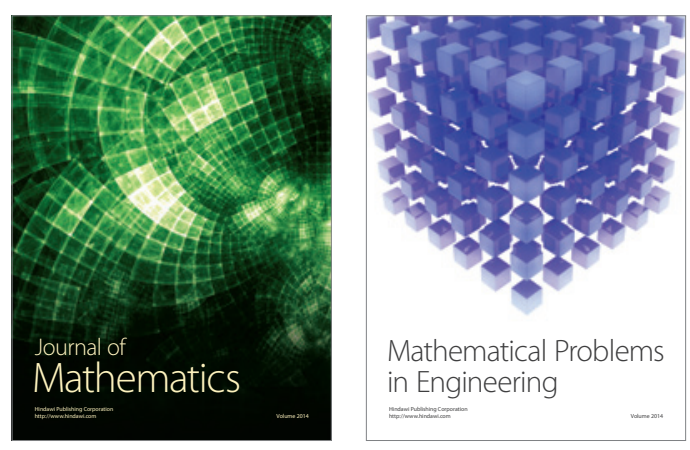

Mathematical Problems in Engineering
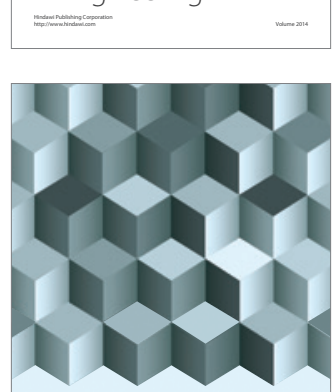

Journal of

Function Spaces
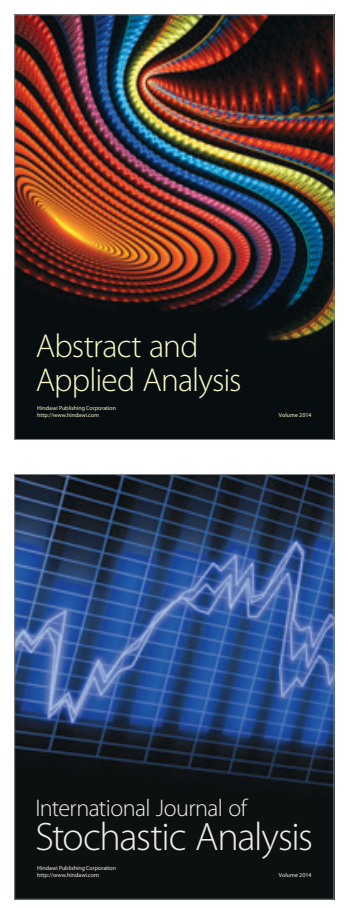

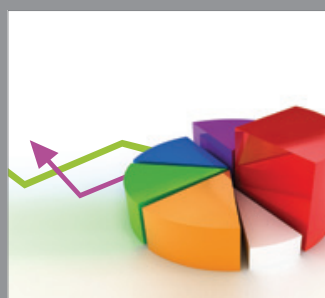

ournal of

Probability and Statistics

Promensencen
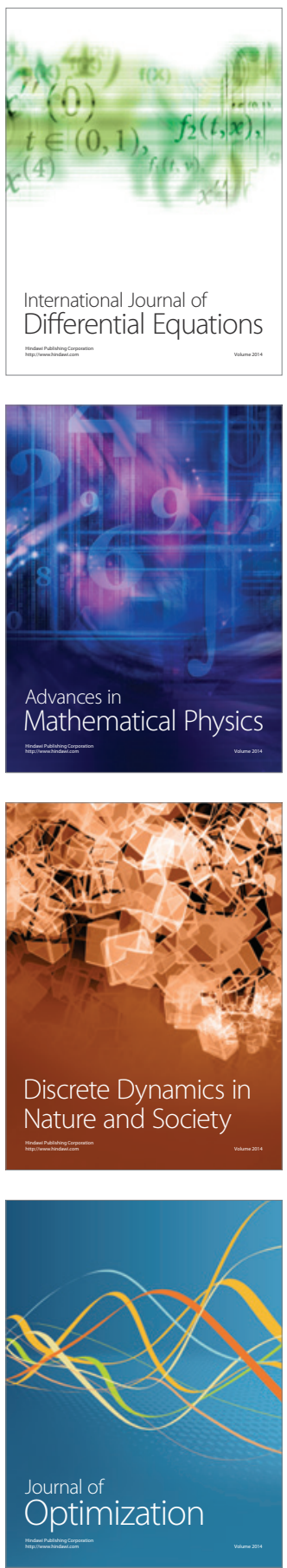